\title{
段違い平行棒運動ロボットの研究 一宙返りを含む移動技の実現—
}

\author{
Study of Uneven Bars Gymnast Robot \\ -Realization of Moving Performance Including Somersault-
}

○学 安藤 豪宣 (法政大院) 高島 俊 (法政大)

関 隆行 (キヤノン)

\author{
Hidenori Andoh ,Hosei University \\ Suguru TAKASHIMA, Hosei University \\ Takayuki SEKI, Canon
}

\begin{abstract}
The goal of this research is to develop a gymnast robot that can perform uneven bars gymnastics. The uneven bars gymnastics is considered to be the expansion of horizontal bar gymnastics in the sense of kinematics. But it has many unique problems in the sense of dynamics. In this paper, the gymnast robot model is modeled in a two dimensional plane as a linked system of three rigid links. The most important maneuver in the gymnastics is to move from one bar to the other bar during the performance. The main target of this paper is to derive the conditions so that the gymnast can reach and grab the other bar after aerial somersault. The research object is that we studied trajectory generation in air using inertia moment of systems and effect of swing motion.
\end{abstract}

Key Words: Gymnast Robot, Uneven Bars, Somersault

\section{1. 緒言}

これまで鉄棒運動に関する研究では，回転運動や倒立動作から， 鉄棒に再び戻るコバチ [1] [2] [3]，着地動作といった空中演技の運動 についての姿勢制御 [4]についての研究が行われている. また，地 面に降りることなく, 異なる支点へ移動する, 連続ブラキエーショ ンについての研究 [5] [6] がなされている.

本研究は, 段違い平行棒運動をすることができるロボットを開発 するための研究である. 段違い平行棒運動におうる動作は, 上記の 文献で用いられている動作とは異なる. 特に, 段違い平行棒運動で は, 空中に固定された 2 点間の移動という, 強い拘束を持った運 動が必要なことと,空中での姿勢制御が厳密に行われる必要がある ことなどで新たな制御手法の提案が求められる. 本報告では, 高棒 から低棒,または低棒から高棒への移動を実現するための方法を確 立することを最終目的とする.段違い平行棒運動ロボットは岡体の 3リンクでモデル化される. 本研究では空中において, 系全体の慣 性モ一メントを操作して姿勢制御し, 適切な姿勢で低棒に到達する ための軌道を示した. また連続的に技を行うための車輸の考察とそ の考察に基づいた車輪軌道の提案を行う.

\section{2. 段違い平行棒運動ロボットのモデルの構築}

\section{1 モデル化}

本研究では, 空中における運動を充分表現でき, 比較的単純化し たモデルを構築する.人間には非常に多くの関節があるが, ほとん どの段違い平行棒運動では, 肘, 膝は伸ばされたままである。そし て，開脚・ひ称りといった運動を扱わなければ 2 次元平面内にある 運動に絞られる.したがって, 以下の仮定のもと, 図 1 に示す岡体 の3リンクでモデル化した.

(1) 肘および膝は曲がらないものとし，1つの岡体とする.

（2）左右の腕, 頭部と胴体, 左右の脚は合体させ，それぞれを 剛体 1 リンクとした 3 リンクモデルとする.

(3) 各リンクの密度は一定とする.

(4) 鉄棒と掌との間には摩擦は無いものとする.

（5）運動は 2 次元平面内のみとする.

（6）各リンクは回転関節で結合されている

$O X Y$ 座標系は, $x$ 軸は右向きを正, $y$ 軸は上向きを正とする. $O^{\prime} X^{\prime} Y^{\prime}$ 座標系は $O X Y$ 座標系に対して回転がなく平行移動したもの
である. モデルパラメータの設定は，実験環境を考慮して，女子の 平均体重・身長の 3 分の 1 程度に設定した. これを表 1 に示寸.

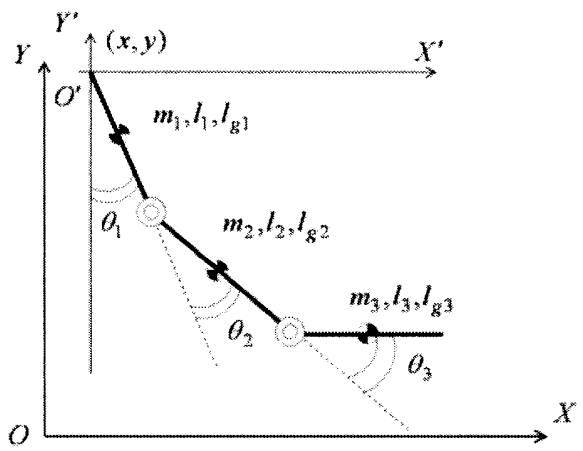

Fig.1 Three-links model of the uneven bars gymnast robot

Table.1 Parameters of the model of the uneven bars gymnast robot

\begin{tabular}{|l||c|c|c|}
\hline & 1st link & 2nd link & 3rd link \\
\hline \hline Mass $m_{i}[\mathrm{~kg}]$ & 0.182 & 0.909 & 0.727 \\
\hline Length $l_{i}[\mathrm{~m}]$ & 0.223 & 0.160 & 0.267 \\
\hline Distance from joint to center of gravity $l_{g i}[\mathrm{~m}]$ & 0.1115 & 0.080 & 0.1335 \\
\hline Moment of inertia $\quad I_{g i}\left[\mathrm{kgm}^{2}\right]$ & 0.00088 & 0.00256 & 0.00482 \\
\hline
\end{tabular}

\section{2 運動方程式}

図 1 のモデルの状態は, 空中での位置を表す手先位置 $(x, y)$ と第 1 リンク絶対角 $\theta_{1}$ および関節相対角 $\theta_{2} ， \theta_{3}$ により表され，5自由 度を持つ. 一般化座標を $q=\left[x, y, \theta_{1}, \theta_{2}, \theta_{3}\right]^{T}$ としLagrange 法により 算出した.

$$
\begin{aligned}
& \qquad\left(q_{i}\right) \ddot{q}_{i}+H\left(q_{i}, \dot{q}_{i}\right)+G\left(q_{i}\right)=F_{i} \\
& \text { ただし, } \\
& q_{i}=\left\{x, y, \theta_{1}, \theta_{2}, \theta_{3}\right\} \\
& F_{i}=\left\{f_{x}, f_{y}, \tau_{1}, \tau_{2}, \tau_{3}\right\}
\end{aligned}
$$

$M\left(q_{i}\right)$ は関節座標に関する慣性行列, $H\left(q_{i}, \dot{q}_{i}\right)$ は遠心力・コリ オリ力項, $G\left(q_{i}\right)$ は重力項である. 


\section{3. 空中姿勢制御手法}

\section{1 空中姿勢制御問題の定式化}

本研究の空中局面を伴う移動技において要求される空中姿勢制 御とは, 空中局面で決められた回数の宙返りを行い, 飛出時刻の初 期姿勢から滞空時間後に目標とする最終姿勢に制御することであ る. そこで, 本研究では空中局面における関節軌道の生成問題を検 証する. 段違い平行棒運動において, 系の合成重心はバーから飛び 出した瞬間から放物運動をする. 空中を自由落下する物体は, 空気 抵抗を無視すれば, 系の運動量と角運動量は保存され, 非ホロノミ ックな拘束条件下で運動を行う。したがって，自由落下中の物体の 運動量と角運動量は, ともに制御できないため, 関節トルクのみを 用いて姿勢を制御する必要がある，そこで本研究では，合成重心ま わりの角速度が適当な值になるように, 合成重心まわりの慣性モ一 メントを操作することにより, 所望とする姿勢でバーに飛びつき, 宙返りによる目標回転量を実現するための姿勢制御手法を提案す る.

\section{2 目標関節軌道生成}

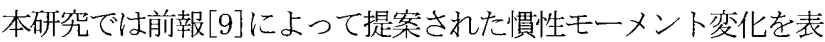
す時間関数を導出することで空中局面関節軌道を生成する.

系全体の慣性モーメント変化を表す時間関数は, 次式のように与 えられる.

$$
\frac{\Theta_{p}}{L}=\int_{t_{0}}^{t_{s}} \frac{1}{I_{g}(t)} d t
$$

ただし，

$\Theta_{p}:$ 宙返りによる回転量

$L:$ 合成重心まわりの角運動量

$I_{g}(t)$ : 合成重心まわりの慣性モーメント

関節軌道の時間関数 $\boldsymbol{\Phi}(t)=\left[\begin{array}{ll}\theta_{2}(t) & \theta_{3}(t)\end{array}\right]^{T}$ で表現できるため, こ の問題は，式(2)を満たす関節軌道の時間関数を導出することと整 理することができる.

しかしながら，式 (2) を満たす関節軌道の時間関数 $\boldsymbol{\Phi}=\left[\begin{array}{ll}\theta_{2}(t) & \theta_{3}(t)\end{array}\right]^{T}$ は無数に存在し, 解析的に一意に決定すること ができない，そのため，関節角に同相運動拘束・逆相運動拘束を与 え, 解析的に導出されることがある. しかし，この導出方法では， 拘束条件によって人間のような自由な動きを再現できないと考え られる. そこで，本研究では人間の自由な動きを再現するために, 関節角に拘束条件を与えず，関節軌道を生成する手法を考える.

\section{a) 最小化問題の適用}

まず，関節軌道の時間関数を $\boldsymbol{\Phi}(t)=\left[\theta_{2}(t) \quad \theta_{3}(t)\right]^{T}$ とし，評価関 数を式(3)のように設定する.ただし，滞空時間は鉄棒間移動実現 条件の際に導出され, 宙返りによる回転量は初期姿勢と最終姿勢よ り導出されるため，これらの值は既定である。

$$
J[\boldsymbol{\Phi}(t)]=\left(\frac{\Theta_{p}}{L}-\int_{t_{v}}^{t_{r}} \frac{1}{I_{g}(\boldsymbol{\Phi}(t))} d t\right)^{2}
$$

しかしここの評価関数を最小にする関節軌道の時間関数を直接求 めることは困難である. そこで，関節軌道 $\boldsymbol{\Phi}(t)=\left[\begin{array}{ll}\theta_{2}(t) & \theta_{3}(t)\end{array}\right]^{T}$ を 有限次元の正規直交基底の一次結合で近似することにより, 評価関 数を最小にする関節軌道の時間関数を求める最小化問題を, 評価関 数を最小にする正規直交基底係数を求める最小化問題に置き換え る. 関節軌道 $\boldsymbol{\Phi}(t)=\left[\begin{array}{ll}\theta_{2}(t) & \theta_{3}(t)\end{array}\right]^{T}$ を無限個の正規直交基底 $e_{i}$ によ
って完全に記述する代わりに，有限次元の正規直交基底 $e_{i}$ で近似 すると, 関節軌道 $\boldsymbol{\Phi}(t)=\left[\begin{array}{ll}\theta_{2}(t) & \theta_{3}(t)\end{array}\right]^{T}$ は次式のように表される.

$$
\boldsymbol{\Phi}(t)=\sum_{i=0}^{N} \boldsymbol{\alpha}_{i} \cdot e_{i}(t)=\boldsymbol{\alpha} \cdot \boldsymbol{E}(t)
$$

ただし，

$\boldsymbol{\alpha}=\left[\boldsymbol{\alpha}_{0}, \boldsymbol{\alpha}_{1}, \boldsymbol{\alpha}_{2}, \cdots, \boldsymbol{\alpha}_{N-1}, \boldsymbol{\alpha}_{N}\right]$ : 正規直交基底係数行列

$\boldsymbol{E}(t)=\left[e_{0}(t), e_{1}(t), e_{2}(t), \cdots, e_{N-1}(t), e_{N}(t)\right]^{T}:$ 正規直交基底べクトル

である.

したがって, 式 $(11)$ の評価関数 $J[\Phi(t)]$ は正規直交基底係数行列 を用いて次のように変形することができる.

$$
J[\alpha]=\left(\frac{\Theta_{p}}{L}-\int_{t_{0}}^{t_{j}} \frac{1}{I_{g}(\alpha)} d t\right)^{2}
$$

以上のことより，式(5)の評価関数を最小にする正規直交基底係 数を探索アルゴリズムまたは組み合わせ最適化アルゴリズムを用 いて探索すればよい. 本研究では，正規直交基底にチェビシェフ多 項式 $T_{k}(t)$ を適用し， $k=10$ までを用いて関節軌道 $\boldsymbol{\Phi}(t)=\left[\begin{array}{ll}\theta_{2}(t) & \theta_{3}(t)\end{array}\right]^{T}$ を近似する. また，評価関数を最小にする正 規直交基底係数の探索には，準ニュートン法(BFGS 法)を用いる.

\section{b）境界条件を満たす正規直交基底係数の決定法}

空中動作は，バーから飛び出す初期時刻 $t=t_{0}$ から，再びバーに 飛びつく最終時刻 $t=t_{f}$ までに, 初期姿勢から目標とする最終姿勢 へと姿勢を変化させる.しかし，式(4)の関節軌道の近似式は，空 中動作の境界条件を満足しておらず，たとえ式(5)の評価関数を最 小にする正規直交基底係数行列を獲得したとしても, 境界条件を満 た寸関節軌道を生成することができない，そこで，あらかじめ境界 条件を満たすように正規直交基底係数行列を決定する方法を考え る. 本研究の関節軌道生成問題における境界条件は, 鉄棒間移動実 現条件を満たすように決定された初期姿勢・初期関節角速度と最終 姿勢である.

<初期条件>

$$
\boldsymbol{\Phi}\left(t_{0}\right)=\left[\theta_{02}(t) \quad \theta_{03}(t)\right]^{T}, \dot{\boldsymbol{\Phi}}\left(t_{0}\right)=\left[\begin{array}{ll}
\dot{\theta}_{02}(t) & \dot{\theta}_{03}(t)
\end{array}\right]^{T}
$$

$<$ 最終条件 $>$

$$
\boldsymbol{\Phi}\left(t_{f}\right)=\left[\begin{array}{ll}
\theta_{t f 2}(t) & \theta_{t f 3}(t)
\end{array}\right]^{T}, \dot{\boldsymbol{\Phi}}\left(t_{f}\right)=\left[\begin{array}{ll}
\dot{\theta}_{t f 2}(t) & \dot{\theta}_{t / 3}(t)
\end{array}\right]^{T}
$$

次に，式(4)の関節軌道の近似式に，式(6)，式(7)の境界条件 $\boldsymbol{\Phi}\left(t_{0}\right), \boldsymbol{\Phi}\left(t_{f}\right), \dot{\boldsymbol{\Phi}}\left(t_{0}\right), \dot{\boldsymbol{\Phi}}\left(t_{f}\right)$ をそれぞれ代入する. すると， $(N+1)$ 個の正規直交基底ベクトルをもつ4個の方程式ができる.したがっ て，4個の正規直交基底べクトルを， $(N-3)$ 個の正規直交基底べ クトルの関係式で表し， $(N-3)$ 個の正規直交基底ベクトルを，準 ニュートン法 (BFGS 法) を用いて, 式(5)の評価関数 $J[\boldsymbol{\alpha}]$ を最小 にするように決定すればよい.この方法により境界条件を確実に満 たす関節軌道を生成することができる.

本研究のチェビシェフ多項式 $T_{10}(t)$ までで関節軌道を近似した 場合を考える.チェビシェフ多項式の高次成分の 4 つの係数ベクト ル $\boldsymbol{\alpha}_{7}, \boldsymbol{\alpha}_{8}, \boldsymbol{\alpha}_{9}, \boldsymbol{\alpha}_{10}$ を，式(4)の近似式に式(6)，式(7)の境界条件 を代入して得られた 4つの方程式より決定する. 次に, 連立方程式 を解くことにより，4つの係数べクトルは，それぞれ境界条件 $\boldsymbol{\Phi}\left(t_{0}\right), \boldsymbol{\Phi}\left(t_{f}\right), \dot{\boldsymbol{\Phi}}\left(t_{0}\right), \dot{\boldsymbol{\Phi}}\left(t_{f}\right)$ と残りの 7 つの係数べクトル 
$\boldsymbol{\alpha}_{0}, \boldsymbol{\alpha}_{1}, \boldsymbol{\alpha}_{2}, \boldsymbol{\alpha}_{3}, \boldsymbol{\alpha}_{4}, \boldsymbol{\alpha}_{5}, \boldsymbol{\alpha}_{6}$ の関係式から計算することができる. そして, 残りの 7 つ係数ベクトルを, 式(5)の評価関数を最小に するように決定する.

3.2 コンピュータシミュレーションによる検証

提案する空中姿勢制御手法の有効性を検証するため, ロボットに 実現させる目標演技を「高棒内向き䀣垂一後方宙返り下移動一低棒 浮支持」（パク宙返りと呼ばれ，高棒から低棒へ移動する空中局面 で宙返りを行う技）とし，2.1 で示した 3 リンクモデルに対して， コンピュータシミュレーションを行った.シミュレーションには MSC Software 社の力学系シミュレーションソフトである Interactive Physics（以下 IP）を使用した. 初期条件は以下のように設定し正 規直交基底として,チェビシェフ多項式を用い各関節角度と角速度 の軌道を生成し, 導出した結果を図 2,3 に示す. 得られた軌道を 用いて, 空中姿勢制御のコンピュータシミュレーションを行った際 の動作アニメーションを図4 に示す.

〈初期条件〉

$$
\begin{aligned}
& \boldsymbol{\theta}_{0}=[60,50,0]^{T} \boldsymbol{\Phi}\left(t_{f}\right)=[55,-85]^{T} \dot{\boldsymbol{\theta}}_{0}=[300,0,0]^{T} \\
& \dot{\boldsymbol{\Phi}}\left(t_{f}\right)=[0,0]^{T} L=0.1980 \quad \Theta_{p}=106.0144 t_{f}=0.3223
\end{aligned}
$$

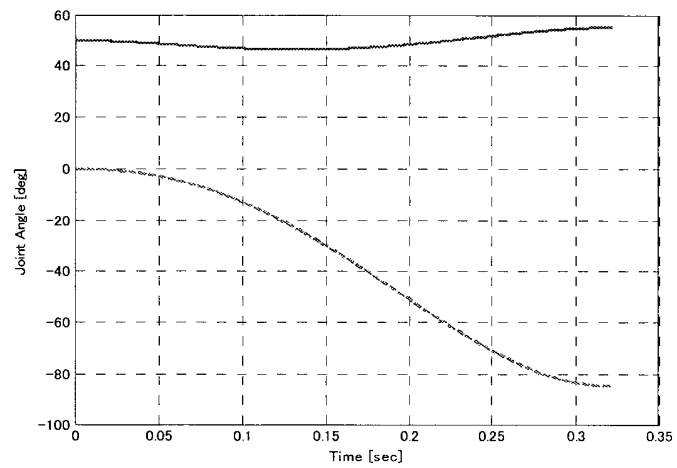

Fig.2 The joint angles

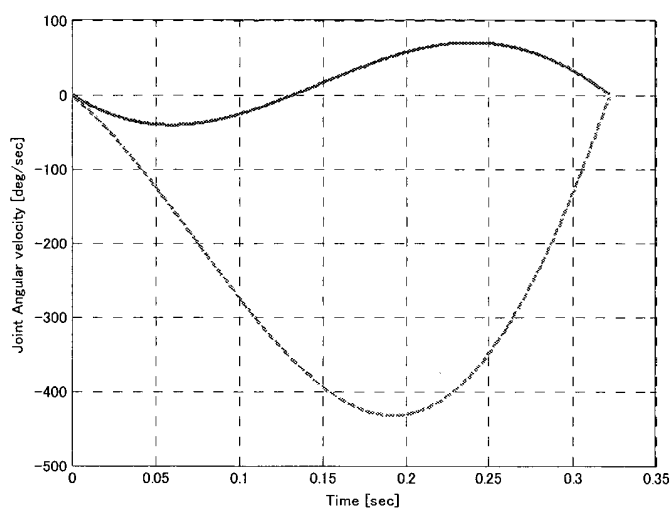

Fig.3 The angular velocities

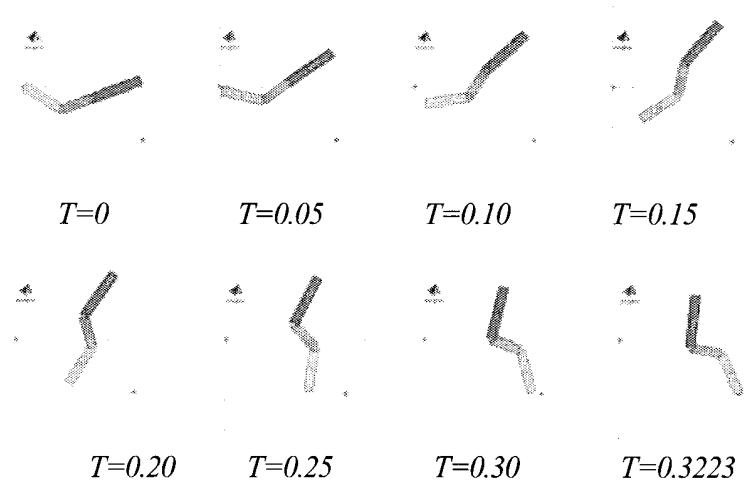

Fig.4 A Simulation result of somersault Pak

\section{4. 車輪軌道生成の手法}

\section{1 車輪軌道生成}

前述では空中姿勢制御手法を提案したが, 空中に飛び出す際の初 期条件は任意に定めたもので実際の車輪軌道から求めてはいない. ここでは車輪軌道の提案を行い倒立姿勢からの車輪によって飛び 出す時の初期姿勢を求める. 本研究で扱うパク宙返りは高棒での静 止した倒立姿勢から始まる技である. 実際にパク宙返りに行く演技 での車輪動作は大車輪とは異なる動作をしている.そこで本研究で は，実際に人が行う動作を検証しパク宙返りをするための車輪軌道 を考える。

a) 動作の検証

まず図 5 のように高棒を中心として 4 つの領域に分割する. 次に 各領域における肩関節と腰関節の動きと各動作の目的を検討する.

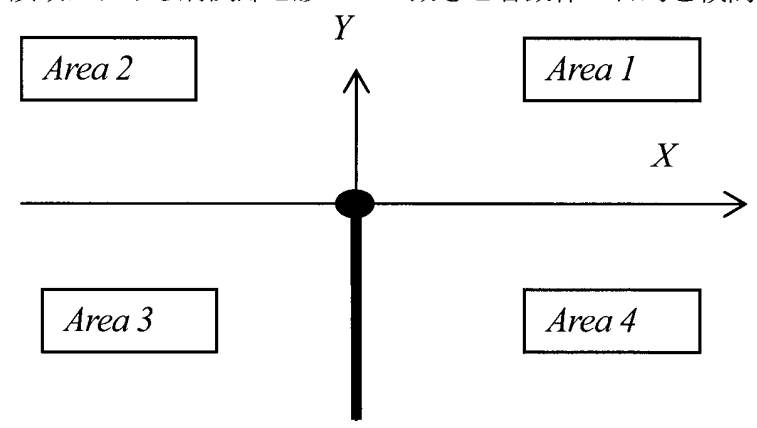

Fig.5 Divided areas of vertical plane around the high bar

合成重心は Area2 $\rightarrow$ Area3 $\rightarrow$ Area4 と移動する. 各領域での動きは 以下の通りである.Area4 では低棒とあたらないようにするため, 腰を曲げる必要性がある.

Area2 : 始動当初, 肩関節は曲げた状態 $\left(\theta_{2}>0\right)$ に腰関節は反つ た状態 $\left(\theta_{3}<0\right)$ になるように動き静止する. その後腰関節 は前方に曲げた状態 $\left(\theta_{3}>0\right)$ になるように動き始め腰関節 が前方に曲げた状態となると肩関節は伸ばした状態 $\left(\theta_{2}\right.$ =0）になるように動き始める.

Area3 : 肩関節は伸ばした状態で維持され，腰関節は前方に曲げ た状態から反った状態になるように動く。

Area 4 : 腰関節反った状態から前方に曲げた状態になるように動 いた後肩関節が曲げた状態になるように動く.渞関節が曲 がり始めると腰関節が伸ばした状態 $\left(\theta_{3}=0\right)$ になるように ゆっくり動く. 
各領域における動作による効果を検討する.Area4 での動きによ って飛び出し時の姿勢や速度が決まるためArea4 から検討する.

Area4 : 腰, 肩の雨関節を曲げるため運動エネルギが増える.つ まり加速動作になる. その後の動作は腰関節と肩関節は相 反する動きをするため大きく速く動かした関節の動作に よって運動エネルギの変化が生じる

Area3 : 腰関節が前方に曲げた状態から反った状態になるように 動くので，運動エネルギが減る。つまり減速動作となる。

Area2 : 初めの動作で合成重心の $y$ 座標成分が小さくなる。つま り位置エネルギが減る.つまり減速動作となる. その後の 動作は腰関節と肩関節は相反する動きをするため大きく 速く動かした関節の動作によって運動エネルギの変化が 生じる.

これにより Area4 では目標とする合成重心の位置にするための 動作であり, Area2 $\rightarrow$ Area3 の動作は減速するための動きであるこ とがいえる.この結果パク宙返りは力を加えない車輪 (自由振動) より遅い車輪でないといけないことがわかった. そのためArea3 で 減速効果を大きくするのが好ましく, Area2 では腰関節は前方に曲 げた状態になる必要性がある.

b) シミュレーションでの検討

4.2 a) で検討した車輪動作による効果をコンピュータシミュ レーションで確認する.今回の車輪軌道は人が行う動作に近い動作 にするため各領域での各関節の目標角度は実際に人が行っている 動画を元にして与えている. またモデルのパラメータを表 2 のよう に変更した. 実際の人と同じサイズにモデルのパラメータをするこ とで感覚的に動作を理解できるようにした. コンピュータシミュレ ーションを行った際の動作アニメーションを図 6 に示す.また自由 振動と今回の車輪軌道における各合成重心の速度と角速度を表 3 に示す.

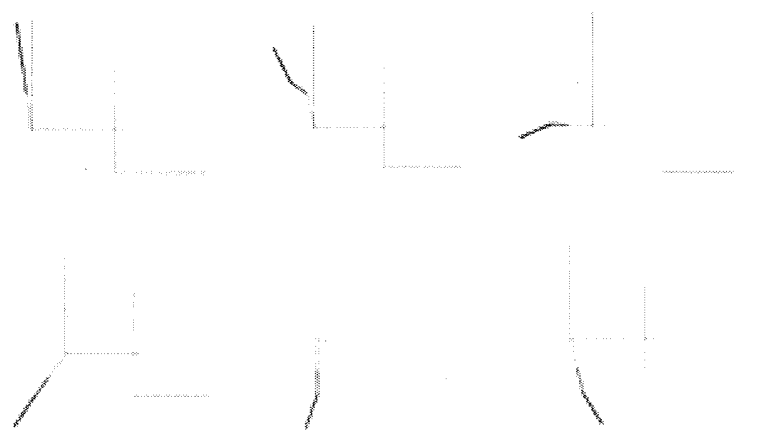

Fig.6 A Simulation results of swing motion

Table.2 Parameters of the model of the uneven bars gymnast robot

\begin{tabular}{|l||c|c|c|}
\hline & 1 st link & 2nd link & 3rd link \\
\hline \hline Mass $m_{i}[\mathrm{~kg}]$ & 0.546 & 2.728 & 2.182 \\
\hline Length $l_{i}[\mathrm{~m}]$ & 0.670 & 0.480 & 0.800 \\
\hline Distancefrom joint to center of gravity $l_{g i}[\mathrm{~m}]$ & 0.335 & 0.240 & 0.400 \\
\hline Moment of inertia $\quad I_{g i}\left[\mathrm{kgm}^{2}\right]$ & 0.070 & 0.500 & 0.420 \\
\hline
\end{tabular}

Table.3 The velocities and angular velocities of the center of gravity

\begin{tabular}{|l||l|r|r|r|}
\hline & $\theta_{g}(\mathrm{rad})$ & -1.57 & 0.00 & 1.20 \\
\hline \hline \multirow{3}{*}{$\begin{array}{l}\text { free } \\
\text { vibration }\end{array}$} & $V x(\mathrm{~m} / \mathrm{s})$ & 0.00 & 5.82 & 1.75 \\
\cline { 2 - 5 } & $V y(\mathrm{~m} / \mathrm{s})$ & -4.10 & 0.00 & 4.50 \\
\cline { 2 - 5 } & $\omega(\mathrm{rad} / \mathrm{s})$ & 3.70 & 5.27 & 4.36 \\
\hline \hline \multirow{3}{*}{ swing } & $V x(\mathrm{~m} / \mathrm{s})$ & 0.07 & 5.00 & 1.40 \\
\cline { 2 - 5 } & $V y(\mathrm{~m} / \mathrm{s})$ & -2.70 & 0.00 & 3.60 \\
\cline { 2 - 5 } & $\omega(\mathrm{rad} / \mathrm{s})$ & 3.25 & 4.69 & 3.60 \\
\hline
\end{tabular}

\section{5. 結言}

本稿では, 宙返りを含み高棒から低棒への移動を実現するための 方法を確立するために，関節角度変化が連続的で，滑らかなとなる ように, 拘束条件を含めた評価関数を導出し目標関節軌道を生成す る手法と飛び出し時の初期条件を決めるための車輪の考察とその 考察に基づく車輪軌道の提案をした。

これを元にして今後は連続的に技を行うために低棒把持後の動 作についても検討していく.

\section{文献}

[1] 大西健介・田中一男・山藤和男, 鉄棒ロボットによるコバチ演技の実現, 日本機械学会ロボティクス・メカトロニクス講演会' 00 講演論文集

[2] 滝田好宏・松田一洋, 鉄棒ロボットによる宙返りの実現（実験による検 証)，日本機械学会論文集，66-648，C(2000)

[3] 滝田好宏・平澤順治, 鉄棒ロボットによる二回宙返りの実現, 日本機械 学会Dynamics and Design Conference 01 論文集

[4] 服部邦雄・山浦弘・小野京右, 浮遊ロボットの姿勢制御（トルク入力の 導出と時変ゲインによる最大トルクの低減), 日本機械学会論文集, 70-691, C (2004-3)

[5] 服部邦雄・山浦弘, 角速度入力による 3 リンク劣駆動浮遊ロボットの姿 勢制御（拘束を用いた姿勢制御戦略），日本機械学会論文集，70-700， C (2004-12)

[6]西村秀和・高崎賢治・舟木厚司・戸谷隆美, 誤差学習による終端状態制 御在用いたブラキエーションロボットの運動制御, 日本機械学会論文集, 63-605, C (1997-1)

[7] 福田敏男・小島盛貴・土井将弘・松野隆幸・長谷川泰久，不等間隔の枝 幅においてのブラキエーションコントローラの解析的設計手法，日本機 械学会ロボティクス・メカトロニクス講演会' 06 講演論文集

[8] 遠藤隆久, 体操競技における空中姿勢の制御及び着地の制御に関する研 究，法政大学大学院機械工学専攻修士論文，1991

[9] 関隆行, 段違い平行棒運動ロボットの研究, 日本機械学会ロボティク ス・メカトロニクス講演会 07 講演論文集

[10] 関隆行, 段違い平行棒運動ロボットの研究, 法政大学大学院機械工学 専攻修士論文，2007 